\title{
Efficacy of Once-Monthly Doses of Oral Afoxolaner and Afoxolaner/Milbemycin Oxime in a Well-Controlled Study for the Treatment of Canine Generalized Demodicosis
}

\author{
Steffen Rehbein'1, Christa de Vos², Frédéric C. Beugnet ${ }^{3}$, Doug S. Carithers ${ }^{4}$, Josephus J. Fourie ${ }^{2}$ \\ ${ }^{1}$ Boehringer Ingelheim, Kathrinenh of Research Center, Rohrdorf, Germany \\ ${ }^{2}$ Clinvet, Universitas, Bloemfontein, South Africa \\ ${ }^{3}$ Boehringer Ingelheim Animal Health, Lyon, France \\ ${ }^{4}$ Boehringer Ingelheim Animal Health, Duluth, GA, USA \\ Email: *doug.carithers@boehringer-ingelheim.com
}

How to cite this paper: Rehbein, S., de Vos, C., Beugnet, F.C., Carithers, D.S. and Fourie, J.J. (2018) Efficacy of Once-Monthly Doses of Oral Afoxolaner and Afoxolaner/Milbemycin Oxime in a Well-Controlled Study for the Treatment of Canine Generalized Demodicosis. Open Journal of Veterinary Medicine, 8, 250-265.

https://doi.org/10.4236/ojvm.2018.812022

Received: October 16, 2018

Accepted: December 25, 2018

Published: December 28, 2018

Copyright $\odot 2018$ by authors and Scientific Research Publishing Inc. This work is licensed under the Creative Commons Attribution International License (CC BY 4.0).

http://creativecommons.org/licenses/by/4.0/

\section{Abstract}

The efficacy of oral treatment with chewable tablets containing afoxolaner $2.27 \%$ w/w (NexGard ${ }^{\circledR}$, Merial, now part of Boehringer-Ingelheim) or $1.875 \%$ $\mathrm{w} / \mathrm{w}$ of afoxolaner and $0.375 \% \mathrm{w} / \mathrm{w}$ milbemycin oxime (NexGard Spectra ${ }^{\circledR}$, Merial, now part of Boehringer-Ingelheim) was each assessed in eight dogs diagnosed with generalized demodicosis in this parallel group designed, blinded, randomized, single center negative controlled, efficacy study. Afoxolaner at the therapeutic dose (as close as possible to $2.5 \mathrm{mg} / \mathrm{kg}$ ) was administered to Group 2 dogs, and afoxolaner (as close as possible to $2.5 \mathrm{mg} / \mathrm{kg}$ ) with milbemycin oxime at $0.5 \mathrm{mg} / \mathrm{kg}$ was administered to Group 3 dogs on Days 0, 28 and 56. All dogs were observed once daily for general health starting on Day -7 until Day 84. All dogs were clinically examined on Days -7 , $-2,14,28,42,56,70$ and 84 . Dogs were weighed on Days $-7,-2,27,55$, and 84. Live mite counts (based on five scrapings per dog and occasion) and clinical assessments, including photographic documentation, were performed on Days -2, 28, 56 and 84. Three monthly treatments with NexGard or NexGard Spectra against generalized demodicosis in dogs were highly effective resulting in a $99.9 \%$ and $100 \%$ efficacy against mites, respectively. After treatment with NexGard, only three live mites were recovered in five scrapings in one dog on Day 84. After treatment with NexGard Spectra, no mites were recovered in any scraping on any dogs in this group by Day 84 . Both treatments resulted in a marked reduction of skin lesions and $>90 \%$ hair-regrowth at three months after the initial treatment. Reduction of live mite counts was 
consistent with reduction in the extent and severity of the skin changes. Although the arithmetic mean mite numbers in the negative control group decreased slightly during the study, infection persisted in 7 of the 8 control dogs until Day 84. Both treatment groups of dogs showed a marked improvement of the associated dermatologic signs with steady improvement over the three-month treatment period.

\section{Keywords}

Demodex canis, Demodicosis, Treatment, Afoxolaner, NexGard, NexGard Spectra, Dog

\section{Introduction}

Demodectic mites (Demodex canis Leydig, 1859) are considered normal fauna of the dog's skin, typically acquired by neonates, from the dam, via skin contact in the first days of life [1] [2] [3]. In individual animals, the mites can proliferate, potentially causing the dog to manifest the parasitic skin disease, canine demodicosis.

Canine demodicosis is classically divided into two clinical presentations, localized and generalized demodicosis. The localized form appears as patchy alopecia on the muzzle or limbs, occasionally with mild erythema in younger dogs, and most cases resolve with time [4]. However, generalized demodicosis results in moderate to severe disease and can even be fatal without appropriate treatment. Generalized demodicosis can occur in both young and old dogs, especially those experiencing immunosuppression, due to systemic disease, parasitism, chemotherapy, malnutrition, or other causes [2] [4] [5].

Historically, generalized demodicosis was a difficult disease to treat effectively, but the isoxazolines have made localized and generalized demodicosis much easier to control. Even though demodicosis is easier to control, the practitioner still must consider the individual cause of generalized demodicosis, especially in young adult dogs. When generalized demodicosis is diagnosed in a young adult dog, international treatment guidance is that the dog should be spayed or neutered [3] [5].

Afoxolaner is an isoxazoline administered monthly to protect dogs against fleas and ticks [NexGard ${ }^{\circledR}$ (afoxolaner) and NexGard Spectra ${ }^{\circledR}$ (afoxolaner/milbemycin oxime)] [6] [7] [8]. It is administered at the minimum therapeutic dose of $2.5 \mathrm{mg} / \mathrm{kg}$. Afoxolaner efficacy against $D$. canis involving dogs diagnosed with generalized demodicosis has been recently demonstrated in a well-controlled laboratory study where dosing occurred on Days $0,14,28$ and 56 [9]. In the well-controlled study described in this paper, dogs with generalized demodicosis were only treated monthly, on Days 0,28 and 56.

\section{Materials and Methods}

\section{Study design and treatment}

The design and conditions of this study were approved by the local Animal 
Welfare Ethics Committee in accordance with Good Clinical Practice by the European Agency for the Evaluation of Veterinary Medicinal Products (CVMP/VICH GL9, July 2000; CVMP/VICH GL19, July 2001) [5]. The dogs were leased from various owners who signed an owner consent form for the inclusion of their dogs in the study. The dogs were returned to their household after completing the study. They originated from Bloemfontein (South Africa) and its suburbs, and were privately owned.

The study followed a randomized block design. The 24 infected dogs included underwent a 7 day acclimation period. On Day -1 , dogs confirmed positive by skin scrapings on Day -2 were included. Dogs were randomly allocated to three groups using total (immature plus adult) live mite counts as ranking criteria. During the acclimation period, two clinical examinations with weighing (Day -7 and Day -2); live mite counts and clinical assessments, including photographic documentation (Day -2); general health observations were recorded daily. Skin biopsies were performed on Day -7 , with enrollment, to ascertain if pyoderma existed. If pyoderma was present, antimicrobial treatment was provided until the pyoderma resolved. Dogs were then randomly allocated to treatment groups, and all evaluations of efficacy were performed by personnel in blinded conditions. The study was conducted on three groups of eight dogs each: Group 1 dogs were untreated controls; Group 2 dogs were treated orally with afoxolaner [NexGard ${ }^{\circledR}(2.27 \%$ w/w chewable tablets)]; and Group 3 dogs were treated orally with a combination of afoxolaner/milbemycin oxime [NexGard Spectra ${ }^{\circledR}$ (1.875\% w/w of afoxolaner and $0.375 \% \mathrm{w} / \mathrm{w}$ milbemycin oxime)] (Table 1$)$. All dogs were weighed and the Group 2 and 3 dogs were administered the investigational veterinary products (IVPs) per os (Table 2). All dogs included in the study were of mixed breeds and at least 6 months of age, with gender and weight on inclusion described (Table 3).

The dogs in Groups 2 and 3 were treated with their respective investigational products on Days 0, 28 and 56. The dogs were observed hourly for four hours after IVP administration to the last animal, for possible adverse events (AEs). Mite counts and clinical assessments, including photographic documentation, were performed on Days 28, 56 and 84. Skin biopsies were performed on Day 27. All dogs were observed once daily for general health starting on Day -7 until Day 84. Twenty-four dogs (10 males and 14 females) weighing 6.1-17.7 kg were included in the study. Females were not pregnant and all dogs were healthy at the initiation of the study, except for clinical signs of generalized demodicosis as determined by a veterinarian on Days -7 and -2 .

Dogs were included in the study if they presented clinical signs of Demodex canis infestations which may have included erythema, hair loss, comedones, follicular casts, scales and crusts. All the dogs presented signs of generalized demodicosis (i.e. more than five spots, pododemodicosis involving two or more paws, or demodicosis of an entire body region). Deep skin scrapings were performed on Day -2 to confirm the presence of Demodex spp. mites. The dogs had not 
been treated with glucocorticoid therapy or any ectoparasiticide or macrocyclic lactone for at least 12 weeks prior to Day 0 , as far as it could be reasonably established by verbal communication with the owners. All dogs considered for inclusion in the study were dewormed prior to Day -7 with a product with no acaricidal activity.

The dogs were housed in kennels consisting of a $1.69 \mathrm{~m} \times 0.7 \mathrm{~m}$ enclosed sleeping area, with panel heaters and an outside run of $1.69 \mathrm{~m} \times 3.0 \mathrm{~m}$. A roof covered the kennels and the dogs were therefore not exposed to rain. The animals were exposed to ambient temperatures and lighting was provided by natural

Table 1. Schedule of operations for the clinical study.

\begin{tabular}{|c|c|}
\hline Day & Procedure \\
\hline-7 to -1 & Acclimation period \\
\hline-7 to $27^{*}$ & Antimicrobial treatment \\
\hline-7 to 84 & $\begin{array}{l}\text { Observed dogs daily for clinical normality } \\
\text { Monitored environmental parameters in cage environment }\end{array}$ \\
\hline-7 & $\begin{array}{l}\text { Clinical examinations } \\
\text { Body weights } \\
\text { Biopsies (food to be removed the afternoon prior to Day }-7 \text { ) }\end{array}$ \\
\hline-2 & $\begin{array}{l}\text { Clinical examinations } \\
\text { Photographic documentation } \\
\text { Mite counts and clinical assessments } \\
\text { Body weights }\end{array}$ \\
\hline-1 & Randomization \\
\hline 0 & $\begin{array}{l}\text { Appropriate treatment dose administration to Groups } 2 \text { and } 3 \text { (according to Day }-2 \text { weight) } \\
\text { Specific post-administration health observation (hourly up to four hours after IVP administration) }\end{array}$ \\
\hline 14 & Clinical examinations \\
\hline 27 & $\begin{array}{l}\text { Body weights } \\
\text { Biopsies }\end{array}$ \\
\hline 28 & $\begin{array}{l}\text { Clinical examinations } \\
\text { Photographic documentation } \\
\text { Mite counts and clinical assessments } \\
\text { Appropriate treatment dose administration to Groups } 2 \text { and } 3 \text { (according to Day } 27 \text { weight) } \\
\text { Specific post-administration health observation (hourly up to four hours after IVP administration) }\end{array}$ \\
\hline 42 & Clinical examinations \\
\hline 55 & Body weights \\
\hline 56 & $\begin{array}{l}\text { Clinical examinations } \\
\text { Photographic documentation } \\
\text { Mite counts and clinical assessments } \\
\text { Appropriate treatment dose administration to Groups } 2 \text { and } 3 \text { (according to Day } 55 \text { weight) } \\
\text { Specific post-administration health observation (hourly up to four hours after IVP administration) }\end{array}$ \\
\hline 70 & Clinical examinations \\
\hline 84 & $\begin{array}{l}\text { Body weights } \\
\text { Clinical examinations } \\
\text { Photographic documentation } \\
\text { Mite counts and clinical assessments }\end{array}$ \\
\hline
\end{tabular}

* Antimicrobial concomitant therapy continued until receipt of the biopsy results. 
Table 2. Dosage recommendation for NexGard ${ }^{\circledR}$ and NexGard Spectra ${ }^{\circledR}$.

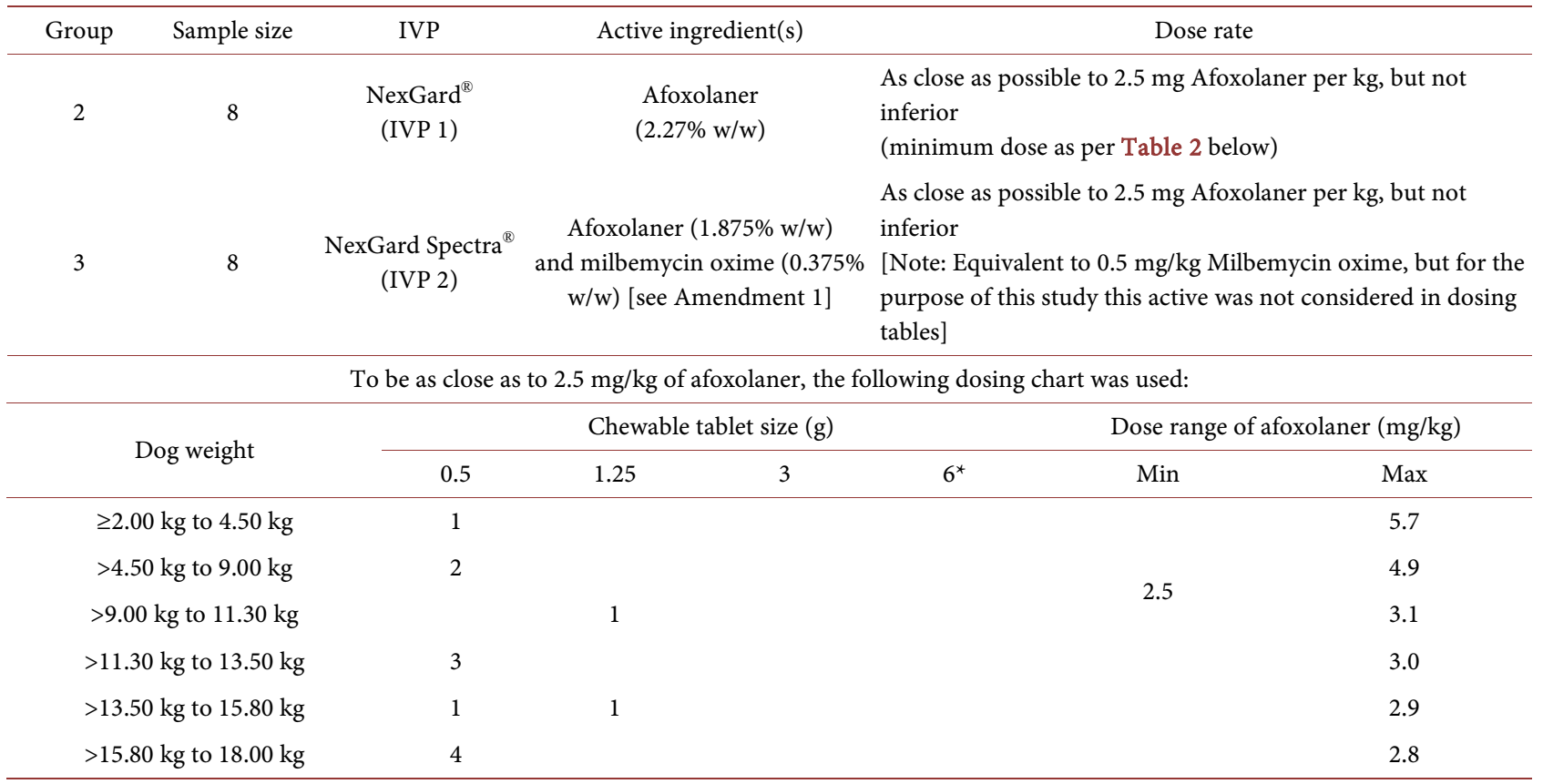

Table 3. Animal details and body weights on inclusion (All dogs were $>6$ months of age).

\begin{tabular}{|c|c|c|c|c|}
\hline Group \# & Animal \# & Gender & Breed & Weight $(\mathrm{kg})$ \\
\hline \multirow[t]{8}{*}{1} & $5 \mathrm{~A} 48 \mathrm{~F} 5$ & Male & Mongrel & 12.86 \\
\hline & 5B3 073 & Female & Mongrel & 6.56 \\
\hline & 689605 & Male & Mongrel & 9.54 \\
\hline & $86 \mathrm{~A}$ BA4 & Female & Mongrel & 10.08 \\
\hline & $86 \mathrm{D} 58 \mathrm{C}$ & Male & Mongrel & 10.14 \\
\hline & 86F 953 & Male & Mongrel & 15.36 \\
\hline & 86A C7D & Male & Mongrel & 17.70 \\
\hline & 885 F87 & Female & Mongrel & 6.08 \\
\hline \multirow[t]{8}{*}{2} & $5 \mathrm{~B} 8 \mathrm{~B} 1 \mathrm{~B}$ & Female & Mongrel & 10.84 \\
\hline & 5D4 C6B & Female & Mongrel & 7.50 \\
\hline & 689 A23 & Male & Mongrel & 6.60 \\
\hline & 5D0 9C4 & Female & Mongrel & 14.44 \\
\hline & 869971 & Female & Mongrel & 6.34 \\
\hline & 86A 263 & Male & Mongrel & 13.72 \\
\hline & 86A B62 & Male & Mongrel & 10.66 \\
\hline & $86 \mathrm{C} \mathrm{C} 8 \mathrm{~B}$ & Female & Mongrel & 7.14 \\
\hline \multirow[t]{8}{*}{3} & 5A9 583 & Female & Mongrel & 11.04 \\
\hline & 689732 & Female & Mongrel & 6.92 \\
\hline & 698 3C9 & Female & Mongrel & 9.66 \\
\hline & $5 \mathrm{~A} 5 \mathrm{D} 30$ & Male & Mongrel & 7.08 \\
\hline & $69856 \mathrm{C}$ & Female & Mongrel & 9.16 \\
\hline & $86 \mathrm{~A} 14 \mathrm{~F}$ & Male & Mongrel & 12.24 \\
\hline & 869 AB4 & Female & Mongrel & 9.84 \\
\hline & 86D 155 & Female & Mongrel & 15.90 \\
\hline
\end{tabular}


sunlight. They were fed once a day and water was provided in stainless steel bowls and replenished at least twice daily. Dogs were fed with standard commercially available animal food at the recommended rates.

Trained personnel under the supervision of a veterinarian were responsible for the health of the animals. Abnormal health signs were reported from daily observations, post-administration observations and scheduled clinical examinations. Authorized concurrent medications included antimicrobials, and vitamin and mineral supplements. The use of concomitant veterinary care and therapy was recorded beginning during the acclimation period through Day 84 .

\section{Assessment of efficacy}

A veterinarian, or qualified member of personnel under the supervision of a veterinarian, conducted a clinical examination on all dogs on Days $-7,-2,14$, 28, 42, 56, 70 and 84. Dogs were also weighed on Days $-7,-2,27,55$, and 84. All the animals were observed daily from Day -7 to Day 84 for general health and from Days 0 to 84 for clinical signs of adverse events to treatment administration.

Efficacy evaluation was based on the decrease in live Demodex spp. mites relative to baseline (Day -2) and the resolution of clinical signs.

\section{Mite counts (primary criterion)}

Deep skin scrapings from five sites were taken on the days of clinical examination. Skin scraping sites were recorded and these sites and/or sites of new lesions were scraped at each subsequent examination. Skin scrapings were made with a scalpel blade so that capillary oozing occurred.

The scraping was transferred to a marked (animal ID, group and body region) microscope slide containing mineral oil and was examined under a stereomicroscope for the presence of live Demodex spp. mites. The number of live mites counted in each scraping was recorded separately.

\section{Clinical symptom evaluation}

The clinical symptoms and the extent of demodectic lesions on each dog were assessed on the same days during which scrapings were made and recorded. The following parameters were assessed for each dog and sketched on a silhouette (left- and right-hand side) of a dog:

- body areas covered by casts, scales and crusts;

- body areas with hair loss $(1=$ slight thinning of hair; $2=$ conspicuous hair loss; 3 = no hair);

- body areas with erythema;

- estimated hair re-growth (Table 4).

Table 4. Semi-quantitative assessment parameters used to score hair re-growth [9].

\begin{tabular}{cr}
\hline Score & Description \\
\hline 1 & Body areas with hair re-growth 0 to $50 \%$ compared to that recorded during the pre-administration assessment \\
2 & Body areas with estimated hair re-growth $>50 \% \leq 90 \%$ compared to that recorded during the pre-administration assessment \\
3 & Body areas with estimated hair re-growth $>90 \%$ compared to that recorded during the pre-administration assessment
\end{tabular}


Colored photographs to illustrate the extent of lesions and the resolution of lesions were taken for each dog before treatment administration (Day -2) and on Days 28, 56 and 84.

\section{Statistical analysis}

The primary assessment variable in this study was the efficacy of the investigational products (IVPs) at the minimum therapeutic dose of $2.5 \mathrm{mg} / \mathrm{kg}$ afoxolaner against mites as compared to controls at each time-point. Due to the fact that small and even zero live mite counts could be recorded, it could be expected that the mite counts would not follow a normal distribution. It was therefore decided that efficacy calculations would be based on geometric means rather than arithmetic means. Before the formal analyses were performed, data were $\log$-transformed $(x=\log (x+1))$. Percentage efficacy for the IVP groups against mites was calculated as follows:

1) Efficacy (\%) against mites $=100 \times(\mathrm{GMc}-\mathrm{GMt}) / \mathrm{GMc}$,

where:

$G M c=$ Geometric Mean number of live mites in dogs in the control group (Group 1).

$G M t=$ Geometric Mean number of live mites in dogs in the treated group (Groups 2 \& 3).

To confirm the acaricidal efficacy results, mite counts were formally analyzed using a Linear Mixed Model. Treatment group was a fixed factor in the model, while the block to which each dog was assigned for randomization was included as a random effect. The IVP groups were compared against the control group using a two-sided F-test with the level of significance set to $\alpha=0.05$.

The secondary assessment was the decrease in live mite counts (immature and adult live mites combined) from pre-administration to each post-administration time point, following IVP administration.

The individual percentage decrease from the pre-administration mite count to the post-administration mite count in each dog on each assessment day was calculated by:

2) Decrease\% (individual) $=($ Pre - administration - Post - administration)/Pre-administration $\times 100$

where:

Pre-administration $=$ the mite counts of a dog prior to the first treatment (Day $-2)$, and

Post-administration $=$ the mite counts of a dog after the relevant treatment.

The average percent reduction in mite counts for the group was calculated by:

Decrease\% (group) $=([$ AMPre - administration - AMPost - administration]/AMPre - administration) $\times 100$

where:

AM Pre-administration $=$ the arithmetic mean $(A M)$ of the pre-administration mites counts, and AM Post-administration = the arithmetic mean of the post-administration mites counts. 
3) The number of mites at each assessment day and for each group was tabulated with the following descriptive statistics: mean, median, standard deviation (SD), geometric mean, minimum and maximum.

The IVP groups were only compared with the control group and not with each other.

The pre-administration and post-administration mite counts were compared by ANOVA with administration (pre or post) and animal effects on mite count data. The level of significance of the formal tests was set at $5 \%$, all tests were two-sided.

SAS Version 9.3 TS Level 1M2 was used for all the statistical analyses.

\section{Clinical signs and symptoms}

Data recorded during clinical assessments on casts, scales, crusts and area(s) of hair loss and erythema were summarized for each dog. Overall changes in clinical appearance were also reported by pre- and post-administration photographs taken from each dog. These results showed the overall extent and resolution of lesions for each dog.

As a secondary criterion, the number of dogs affected by erythema, casts, scales and crusts was compared between the pre-administration and different post-administration assessment days. A semi-quantitative assessment of hair re-growth was also conducted and a score awarded to each dog on the different post-administration assessment days (Table 3). Photographic documentation was used to highlight changes in skin condition (Figures 1-3).

\section{Results}

\section{Antiparasitic efficacy}

Efficacy against $D$. canis, using geometric means, is summarized in Table 5.

All the dogs were positive for the presence of mites prior to the first treatment. For both treated groups on all post-treatment assessment days, the mite counts were statistically significantly reduced $(\mathrm{p}<0.05)$ compared to the counts at initiation (Day -2) (Table 5). The geometric mean number of live mites recorded on the dogs prior to IVP treatment administration was 270.2 in Group 1 (negative control), 306.3 in Group 2 (NexGard) and 262.8 in Group 3 (NexGard Spectra),

Table 5. Efficacy of treatment groups against Demodex canis (based on geometric means).

\begin{tabular}{|c|c|c|c|c|c|c|c|}
\hline \multirow{3}{*}{ Day } & \multicolumn{7}{|c|}{ Control } \\
\hline & \multirow{2}{*}{$\begin{array}{l}\text { Group } 1 \\
\text { Mean }\end{array}$} & \multicolumn{3}{|c|}{ Group 2} & \multicolumn{3}{|c|}{ Group 3} \\
\hline & & Mean & $\begin{array}{c}\text { Percentage } \\
\text { efficacy }\end{array}$ & p-value & Mean & $\begin{array}{c}\text { Percentage } \\
\text { efficacy }\end{array}$ & $\mathrm{p}$-value \\
\hline Day 28 & 87.4 & 2.9 & 96.7 & $<0.0001$ & 1.4 & 98.4 & $<0.0001$ \\
\hline Day 56 & 197.6 & 0.1 & $>99.9$ & $<0.0001$ & 0.1 & $>99.9$ & $<0.0001$ \\
\hline Day 84 & 140.9 & 0.2 & 99.9 & $<0.0001$ & 0.0 & 100 & $<0.0001$ \\
\hline
\end{tabular}

Group 1: Negative control; Group 2: Dogs were treated orally with the IVP NexGard ${ }^{\mathbb{R}}$; Group 3: Dogs were treated orally with the IVP NexGard Spectra ${ }^{\circledR}$. 
indicating demodectic mange infestations in each group. The mite counts did not differ significantly between the different treatment groups $(p=0.9565)$. After IVP treatment administration, mite infestations persisted in all but one dog in the negative control group 1 for the duration of the assessment period, with geometric mean counts ranging from 87.4 to 197.6 for the group.

A single treatment with NexGard resulted in a significant decrease in live mites (mean $=2.9$ ) at Day 28 with the subsequent monthly treatments resulting in a further decrease to a mean of 0.2 mites for the group on Day 84 . Similarly a single treatment with NexGard Spectra reduced the infestations significantly to a mean mite count of 1.4 on Day 28, and with the subsequent assessments (and two additional treatments) no mites were recovered in any of the scrapings on any of the dogs.

\section{$\%$ decrease in mite counts}

The number of live $D$. canis mites based on skin scrapings (individual) and corresponding percentage reductions for each assessment day is summarized in Tables 6-8 and percentage decrease per group in Table 9.

The arithmetic mean mite counts recorded in the negative control group decreased from baseline (Day -2) to $48.8 \%$ on Day $28,12.0 \%$ on Day 56 and $11.6 \%$

Table 6. Individual and summary statistics of decrease in D. canis mite counts (Group 1).

\begin{tabular}{|c|c|c|c|c|c|c|c|c|c|c|}
\hline \multirow{2}{*}{ Animal ID/ Statistic } & \multirow{2}{*}{$\begin{array}{l}\text { Baseline } \\
(\text { Day }-2)\end{array}$} & \multicolumn{3}{|c|}{ Day 28} & \multicolumn{3}{|c|}{ Day 56} & \multicolumn{3}{|c|}{ Day 84} \\
\hline & & $\mathrm{N}$ & Decrease & $\%$ Decrease & $\mathrm{N}$ & Decrease & $\%$ Decrease & $\mathrm{N}$ & Decrease & $\%$ Decrease \\
\hline 5A4 8F5 & 69 & 13 & 56 & 81.2 & 36 & 33 & 47.8 & 0 & 69 & 100 \\
\hline 5B3 073 & 459 & 796 & -337 & 0 & & & & & & \\
\hline 689605 & 227 & 99 & 128 & 56.4 & 729 & -502 & 0.0 & 309 & -82 & 0.0 \\
\hline 86A BA4 & 871 & 195 & 676 & 77.6 & 188 & 683 & 78.4 & 263 & 608 & 69.8 \\
\hline 86A C7D & 140 & 26 & 114 & 81.4 & 101 & 39 & 27.9 & 256 & -116 & 0.0 \\
\hline $86 \mathrm{D} 58 \mathrm{C}$ & 197 & 128 & 69 & 35.0 & 751 & -554 & 0.0 & 443 & -246 & 0.0 \\
\hline $86 \mathrm{~F} 953$ & 639 & 180 & 459 & 71.8 & 106 & 533 & 83.4 & 158 & 481 & 75.3 \\
\hline 885 F87 & 255 & 26 & 229 & 89.8 & 290 & -35 & 0.0 & 781 & -526 & 0.0 \\
\hline $\mathrm{n}$ & 8 & 8 & 8 & 8 & 7 & 7 & 7 & 7 & 7 & 7 \\
\hline Mean & 357.1 & 182.9 & 174.3 & 61.66 & 314.4 & 28.1 & 33.93 & 315.7 & 26.9 & 35.01 \\
\hline $\mathrm{SD}$ & 276.99 & 257.52 & 299.53 & 30.38 & 301.54 & 466.87 & 36.77 & 246.18 & 399.61 & 44.60 \\
\hline CV\% & 77.6 & 140.8 & 171.9 & 49.3 & 95.9 & 1658.9 & 108.4 & 78.0 & 1487.9 & 127.5 \\
\hline GeoMean & 270.2 & 87.4 & 169.8 & 39.5 & 197.6 & 148.3 & 8.9 & 140.9 & 272.9 & 5.6 \\
\hline Median & 241.0 & 113.5 & 121.0 & 74.7 & 188.0 & 33.0 & 27.9 & 263.0 & -82.0 & 0.0 \\
\hline Minimum & 69 & 13 & -337 & 0.0 & 36 & -554 & 0.0 & 0 & -526 & 0.0 \\
\hline Maximum & 871 & 796 & 676 & 89.8 & 751 & 683 & 83.4 & 781 & 608 & 100 \\
\hline
\end{tabular}

N: Actual mite counts; Decrease $=$ Pre-administration mite count - Post-administration mite count; \% Decrease $=(($ Pre-administration mite count Post-administration mite count)/Pre-administration mite count) ${ }^{\star} 100$; Group 1: Negative control; Group 1, Dog \#5B3 073 was removed from the study for health reasons. 
Table 7. Individual and summary statistics of decrease in D. canis mite counts (Group 2).

\begin{tabular}{|c|c|c|c|c|c|c|c|c|c|c|}
\hline \multirow{2}{*}{$\begin{array}{l}\text { Animal ID/ } \\
\text { Statistic }\end{array}$} & \multirow{2}{*}{$\begin{array}{l}\text { Baseline } \\
(\text { Day -2) }\end{array}$} & \multicolumn{3}{|c|}{ Day 28} & \multicolumn{3}{|c|}{ Day 56} & \multicolumn{3}{|c|}{ Day 84} \\
\hline & & $\mathrm{N}$ & Decrease & $\%$ Decrease & $\mathrm{N}$ & Decrease & $\%$ Decrease & $\mathrm{N}$ & Decrease & $\%$ Decrease \\
\hline $5 B 8 \mathrm{~B} 1 \mathrm{~B}$ & 301 & 35 & 266 & 88.4 & 2 & 299 & 99.3 & 0 & 301 & 100 \\
\hline 5D0 9C4 & 1254 & 46 & 1208 & 96.3 & 0 & 1254 & 100 & 0 & 1254 & 100 \\
\hline 5D4 C6B & 212 & 4 & 208 & 98.1 & 0 & 212 & 100 & 0 & 212 & 100 \\
\hline 689 A23 & 121 & 0 & 121 & 100 & 0 & 121 & 100 & 0 & 121 & 100 \\
\hline 869971 & 286 & 2 & 284 & 99.3 & 0 & 286 & 100 & 0 & 286 & 100 \\
\hline 86 A 263 & 421 & 0 & 421 & 100 & 0 & 421 & 100 & 0 & 421 & 100 \\
\hline 86 A B62 & 144 & 0 & 144 & 100 & 0 & 144 & 100 & 3 & 141 & 97.9 \\
\hline 86C C8B & 459 & 1 & 458 & 99.8 & 0 & 459 & 100 & 0 & 459 & 100 \\
\hline $\mathrm{n}$ & 8 & 8 & 8 & 8 & 8 & 8 & 8 & 8 & 8 & 8 \\
\hline Mean & 399.8 & 11.0 & 388.8 & 97.7 & 0.3 & 399.5 & 99.9 & 0.4 & 399.4 & 99.7 \\
\hline SD & 365.43 & 18.49 & 352.00 & 4.00 & 0.71 & 365.50 & 0.24 & 1.06 & 365.73 & 0.74 \\
\hline CV\% & 91.4 & 168.1 & 90.5 & 4.1 & 282.8 & 91.5 & 0.2 & 282.8 & 91.6 & 0.7 \\
\hline GeoMean & 306.3 & 2.9 & 299.2 & 97.7 & 0.1 & 306.1 & 99.9 & 0.2 & 305.5 & 99.7 \\
\hline Median & 293.5 & 1.5 & 275.0 & 99.5 & 0.0 & 292.5 & 100 & 0.0 & 293.5 & 100 \\
\hline Minimum & 121 & 0 & 121 & 88.4 & 0 & 121 & 99.3 & 0 & 121 & 97.9 \\
\hline Maximum & 1254 & 46 & 1208 & 100 & 2 & 1254 & 100 & 3 & 1254 & 100 \\
\hline
\end{tabular}

N: Actual mite counts; Decrease $=$ Pre-administration mite count - Post-administration mite count; \% Decrease $=(($ Pre-administration mite count Post-administration mite count)/Pre-administration mite count) ${ }^{\star} 100$; Group 2: Dogs were treated orally with the IVP NexGard ${ }^{\circledR}$.

Table 8. Individual and summary statistics of decrease in D. canis mite counts (Group 3).

\begin{tabular}{|c|c|c|c|c|c|c|c|c|c|c|}
\hline \multirow{2}{*}{$\begin{array}{l}\text { Animal ID/ } \\
\text { Statistic }\end{array}$} & \multirow{2}{*}{$\begin{array}{l}\text { Baseline } \\
(\text { Day -2) }\end{array}$} & \multicolumn{3}{|c|}{ Day 28} & \multicolumn{3}{|c|}{ Day 56} & \multicolumn{3}{|c|}{ Day 84} \\
\hline & & $\mathrm{N}$ & Decrease & \% Decrease & $\mathrm{N}$ & Decrease & $\%$ Decrease & $\mathrm{N}$ & Decrease & $\%$ Decrease \\
\hline 5A5 D30 & 377 & 33 & 344 & 91.2 & 0 & 377 & 100 & 0 & 377 & 100 \\
\hline 5A9 583 & 136 & 0 & 136 & 100 & 0 & 136 & 100 & 0 & 136 & 100 \\
\hline 689732 & 148 & 0 & 148 & 100 & 0 & 148 & 100 & 0 & 148 & 100 \\
\hline 698 3C9 & 256 & 0 & 256 & 100 & 0 & 256 & 100 & 0 & 256 & 100 \\
\hline $69856 \mathrm{C}$ & 226 & 3 & 223 & 98.7 & 1 & 225 & 99.6 & 0 & 226 & 100 \\
\hline 869 AB4 & 1074 & 0 & 1074 & 100 & 0 & 1074 & 100 & 0 & 1074 & 100 \\
\hline $86 \mathrm{~A} 14 \mathrm{~F}$ & 969 & 8 & 961 & 99.2 & 0 & 969 & 100 & 0 & 969 & 100 \\
\hline 86D 155 & 49 & 0 & 49 & 100 & 0 & 49 & 100 & 0 & 49 & 100 \\
\hline $\mathrm{n}$ & 8 & 8 & 8 & 8 & 8 & 8 & 8 & 8 & 8 & 8 \\
\hline Mean & 404.4 & 5.5 & 398.9 & 98.6 & 0.1 & 404.3 & 99.9 & 0.0 & 404.4 & 100 \\
\hline $\mathrm{SD}$ & 393.85 & 11.46 & 392.90 & 3.03 & 0.35 & 393.92 & 0.16 & 0.00 & 393.85 & 0.00 \\
\hline CV\% & 97.4 & 208.4 & 98.5 & 3.1 & 282.8 & 97.4 & 0.2 & & 97.4 & 0.0 \\
\hline GeoMean & 262.8 & 1.4 & 259.1 & 98.59 & 0.1 & 262.7 & 99.94 & 0.0 & 262.8 & 100 \\
\hline Median & 241.0 & 0.0 & 239.5 & 100 & 0.0 & 240.5 & 100 & 0.0 & 241.0 & 100 \\
\hline Minimum & 49 & 0 & 49 & 91.2 & 0 & 49 & 99.6 & 0 & 49 & 100 \\
\hline Maximum & 1074 & 33 & 1074 & 100 & 1 & 1074 & 100 & 0 & 1074 & 100 \\
\hline
\end{tabular}

$\mathrm{N}$ : Actual mite counts; Decrease $=$ Pre-administration mite count - Post-administration mite count; \% Decrease $=(($ Pre-administration mite count Post-administration mite count)/Pre-administration mite count) ${ }^{\star} 100$; Group 3: Dogs were treated orally with the IVP NexGard Spectra ${ }^{\circledR}$. 
Table 9. Per group statistics of decrease in D. canis mite counts based on arithmetic means.

\begin{tabular}{cccccccccccc}
\hline & $\begin{array}{c}\text { AM } \\
\text { Group } \\
\text { baseline } \\
(\text { Day -2) }\end{array}$ & AM & Decrease & $\begin{array}{c}\text { Day } 28 \\
\text { Decrease }\end{array}$ & AM & Decrease & $\begin{array}{c}\text { \% } \\
\text { Decrease }\end{array}$ & AM & Decrease & $\%$ \\
1 & 357.1 & 182.9 & 174.3 & 48.8 & 314.4 & 42.7 & 12.0 & 315.7 & 41.4 & 11.6 \\
2 & 399.8 & 11.0 & 388.8 & 97.2 & 0.3 & 399.5 & 99.9 & 0.4 & 399.4 & 99.9 \\
3 & 404.4 & 5.5 & 398.9 & 98.6 & 0.1 & 404.3 & $>99.9$ & 0.0 & 404.4 & 100 \\
\hline
\end{tabular}

AM: Arithmetic mean; Decrease $=$ AM Pre-administration mite count - AM Post-administration mite count; \% Decrease $=(($ AM Pre-administration mite count - AM Post-administration mite count $) /$ AM Pre-administration mite count) ${ }^{\star} 100$; Group 1: Negative control; Group 2: Dogs were treated orally with the IVP NexGard ${ }^{\mathbb{B}}$; Group 3: Dogs were treated orally with the IVP NexGard Spectra ${ }^{\mathbb{B}}$.

on Day 84. Demodectic mite infestations persisted in all but one control dog up to Day 84. After the first treatment with NexGard, the arithmetic mean mite counts decreased to $97.2 \%$ on Day 28 and $99.9 \%$ on Days 56 and 84 . One dog harbored three mites on Day 84 but that individual had a $97.9 \%$ reduction in mite numbers from baseline.

After the first treatment with NexGard Spectra, the arithmetic mean mite counts decreased to $98.6 \%$ on Day $28,>99.9 \%$ on Day 56 , and with $100 \%$ on Day 84. No mites were recovered in any skin scrapings from any of the dogs in this group on Day 84 .

\section{Clinical efficacy}

During the assessments of clinical signs and symptoms related to demodicosis, the following were concluded: in Group 1 (negative control), the occurrence of crusts remained rather similar and occurrence of both casts and scales increased by Day 84. In Group 2 (NexGard), the occurrence of crusts decreased and no casts and scales were present by Day 84. In Group 3 (NexGard Spectra), no crusts and scales were present by Day 84. Erythematous papules were never observed for any of the groups. The occurrence of crusts, casts and scales at pre-treatment evaluations as well as the resolution thereof during the post-treatment assessment period, are summarized in Table 10 for the three groups.

Hair re-growth, where the percentage of hair re-growth was compared to the recorded hair growth prior to IVP treatment, is summarized in Table 11.

Since resolution of clinical signs, including alopecia, is the desired clinical outcome, analyses $>90 \%$ v. $<90 \%$ were statistically compared for the groups. Fisher's Exact Test for Count Data; Alternative: 2-sided. [10] was used for these analyses, as it allows comparison with groups at 0 , which is not possible with $\mathrm{Chi}^{2}$. These results are shown in Table 12.

All IVP treated dogs showed $>90 \%$ hair regrowth on Day 84 , which can be seen in the photographic documentation (Figures 1-3).

\section{Health observations}

Due progressive health deterioration associated with demodicosis, of one of the dogs in the negative control group, had to be humanely euthanized. The 
treatment of the dogs with Nexgard ${ }^{\circledR}$ and Nexgard Spectra ${ }^{\circledR}$ (respectively) were however well accepted and no investigational product-related health abnormalities were observed throughout the study.

Table 10. Frequency and percentage counts of the individual clinical signs.

\begin{tabular}{ccccc}
\hline Group & Day & Crust & Casts & Scales \\
\hline 1 & Day -2 & $6 / 8(75.0 \%)$ & $1 / 8(12.5 \%)$ & $4 / 8(50.0 \%)$ \\
& Day 28 & $5 / 8(62.5 \%)$ & $1 / 8(12.5 \%)$ & $3 / 8(37.5 \%)$ \\
& Day 56 & $5 / 7(71.4 \%)$ & $0 / 7(0.0 \%)$ & $1 / 7(14.3 \%)$ \\
& Day 84 & $5 / 7(71.4 \%)$ & $4 / 7(57.1 \%)$ & $5 / 7(71.4 \%)$ \\
2 & Day -2 & $2 / 8(25.0 \%)$ & $1 / 8(12.5 \%)$ & $5 / 8(62.5 \%)$ \\
& Day 28 & $3 / 8(37.5 \%)$ & $0 / 8(0.0 \%)$ & $3 / 8(37.5 \%)$ \\
& Day 56 & $2 / 8(25.0 \%)$ & $0 / 8(0.0 \%)$ & $0 / 8(0.0 \%)$ \\
& Day 84 & $1 / 8(12.5 \%)$ & $0 / 8(0.0 \%)$ & $0 / 8(0.0 \%)$ \\
& Day -2 & $1 / 8(12.5 \%)$ & $2 / 8(25.0 \%)$ & $4 / 8(50.0 \%)$ \\
& Day 28 & $0 / 8(0.0 \%)$ & $0 / 8(0.0 \%)$ & $1 / 8(12.5 \%)$ \\
& Day 56 & $1 / 8(12.5 \%)$ & $0 / 8(0.0 \%)$ & $1 / 8(12.5 \%)$ \\
& Day 84 & $0 / 8(0.0 \%)$ & $0 / 8(0.0 \%)$ & $1 / 8(12.5 \%)$ \\
\hline
\end{tabular}

Table 11. Percentage hair re-growth during the assessment period.

\begin{tabular}{|c|c|c|c|c|c|c|c|c|c|}
\hline \multirow{4}{*}{ Day } & \multicolumn{9}{|c|}{ Estimated percentage hair re-growth } \\
\hline & & Group 1 & & \multicolumn{3}{|c|}{ Group 2} & \multicolumn{3}{|c|}{ Group 3} \\
\hline & \multicolumn{3}{|c|}{$\begin{array}{c}\text { (number of dogs/number of } \\
\text { dogs per group) }\end{array}$} & $\begin{array}{r}\text { (number } \\
\text { dog }\end{array}$ & $\begin{array}{l}\text { of dogs/num } \\
\text { s per group) }\end{array}$ & nber of & (number & $\begin{array}{l}\text { f dogs/numb } \\
\text { per group) }\end{array}$ & of dogs \\
\hline & $0 \%-50 \%$ & $50 \%-90 \%$ & $>90 \%$ & $0 \%-50 \%$ & $50 \%-90 \%$ & $>90 \%$ & $0 \%-50 \%$ & $50 \%-90 \%$ & $>90 \%$ \\
\hline 28 & $8 / 8$ & - & - & $2 / 8$ & $6 / 8$ & - & $4 / 8$ & $4 / 8$ & - \\
\hline 56 & $6 / 7$ & $1 / 7$ & - & - & $5 / 8$ & $3 / 8$ & - & - & $8 / 8$ \\
\hline 84 & - & $7 / 7$ & - & - & - & $8 / 8$ & - & - & $8 / 8$ \\
\hline
\end{tabular}

Group 1: Negative control; Group 2: Dogs were treated orally with the IVP NexGard ${ }^{\circledR}$; Group 3: Dogs were treated orally with the IVP NexGard Spectra ${ }^{\circledR}$.

Table 12. Resolution of clinical signs, as indicated by $>90 \%$ hair regrowth.

\begin{tabular}{ccccc}
\hline & & Group 1 & Group 2 & Group 3 \\
\hline \multirow{2}{*}{ Day 28 } & $>90 \%$ regrowth & 0 & 0 & 0 \\
& $<90 \%$ regrowth & 8 & 8 & 8 \\
Day 56 & $>90 \%$ regrowth & 0 & 3 & $8^{\mathrm{A}, \mathrm{B}}$ \\
& $<90 \%$ regrowth & 7 & 5 & 0 \\
Day 84 & $>90 \%$ regrowth & 0 & $8^{\mathrm{C}}$ & $8^{\mathrm{C}}$ \\
& $<90 \%$ regrowth & 7 & 0 & 0 \\
\hline
\end{tabular}

${ }^{A}$ Statistically different from Group 1 (control) for the same day ( $\left.p<0.0001\right)$; ${ }^{B}$ Statistically different from Group 2 for the same day $(\mathrm{p}<0.0257)$; ${ }^{\mathrm{C}}$ Statistically different from Group 1 for the same day $(\mathrm{p}<0.0001)$. 
Day 0

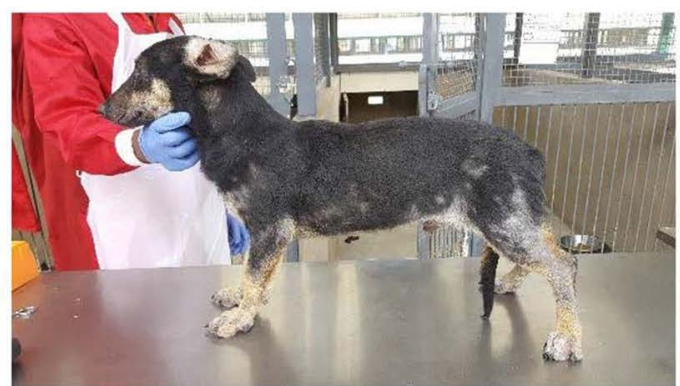

Day 56

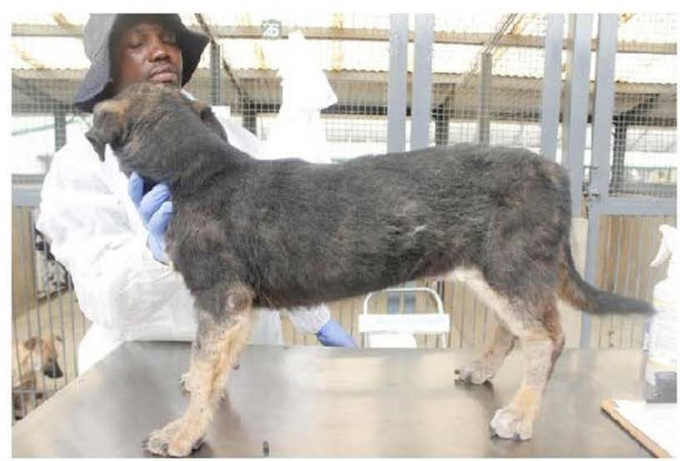

Day 28

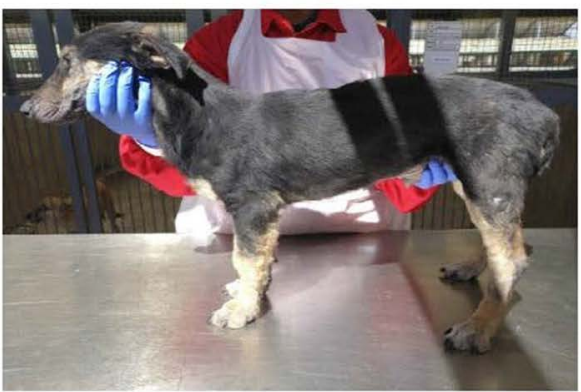

Day 84

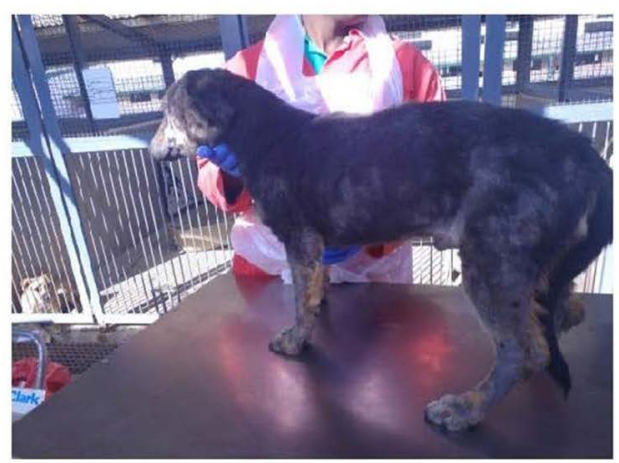

Figure 1. Untreated control dog prior to Day 0, and on Days 28, 56 and 84.

Day 0

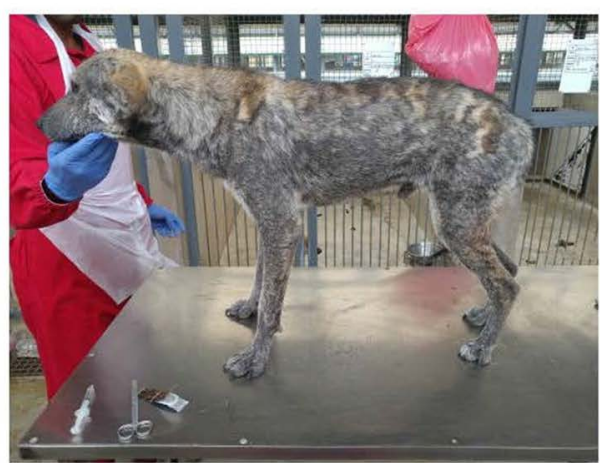

Day 56

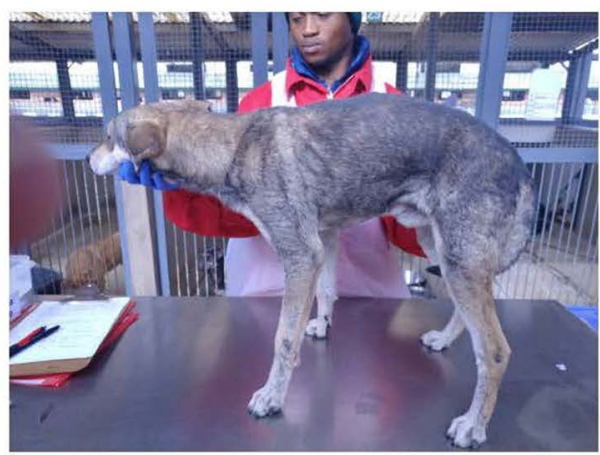

Day 28

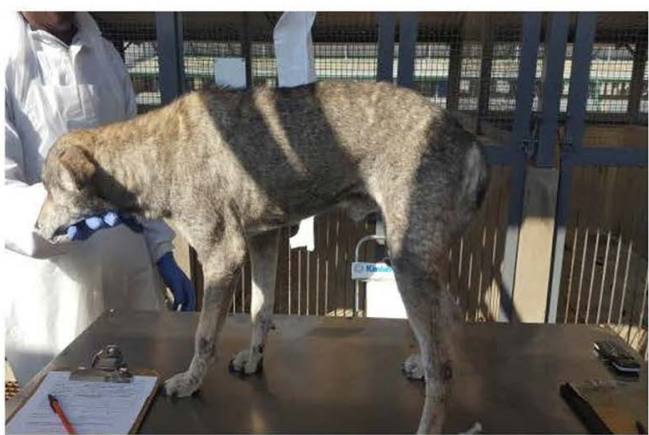

Day 84

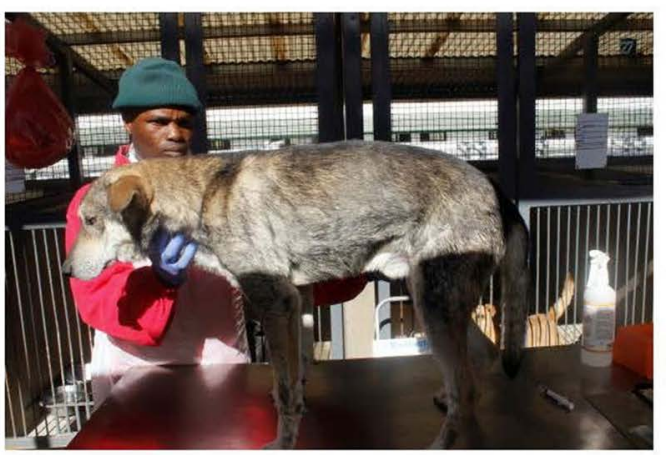

Figure 2. NexGard treated dog prior to Day 0, and on Days 28, 56 and 84. 
Day 0

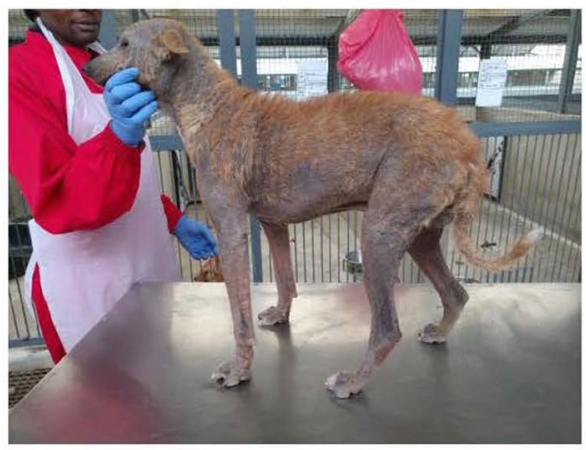

Day 56

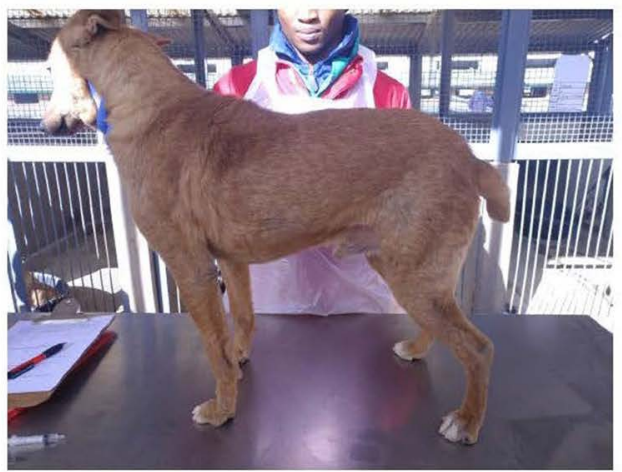

Day 28

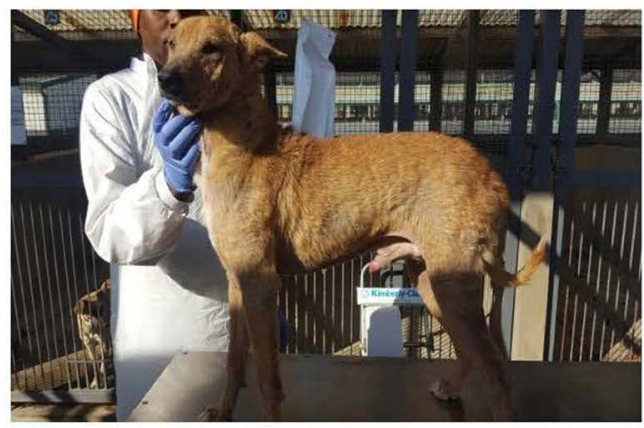

Day 84

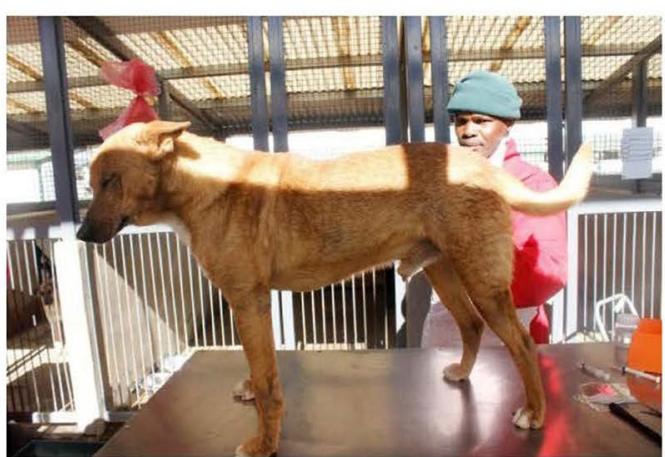

Figure 3. NexGard Spectra treated dog prior to Day 0, and on Days, 28, 56 and 84.

\section{Discussion and Conclusion}

An initial clinical assessment of afoxolaner activity against demodectic mange was done with bi-weekly treatments with NexGard at Days 0, 14 and then 28, a strategy based, in-part, on rapidly achieving a steady state of afoxolaner in the blood of the study animals [6]. This was considered to be safe because this schedule was performed in the NexGard and NexGard Spectra target animal safety studies conducted for its registration in the USA and Europe [7] [8]. In those studies, no adverse events related to the treatment were observed during the time that three doses were administered biweekly. The bi-weekly protocol was highly effective, but necessity of the shortened dosing interval for treatment of demodicosis was questioned by the authors [9]. Nearly simultaneously, field reports of high efficacy with regular (monthly) dosing demonstrated that the higher systemic drug levels afforded by bi-weekly dosing may not be necessary to clear demodectic mites [11].

This well-controlled study was initiated, and it validated the field reports of Chavez and others [12] demonstrating outstanding efficacy was provided by regular monthly dosing of afoxolaner against demodectic mange. In this study, based on geometric mean mite counts, a single treatment with NexGard resulted in a $96.7 \%$ efficacy on Day 28 with the two subsequent monthly treatments increasing the efficacy slightly to $99.9 \%$. Only three mites were recovered from the 
skin scrapings of one dog on Day 84. A single treatment with NexGard Spectra resulted in a $98.4 \%$ efficacy on Day 28 with the two subsequent monthly treatments completely eliminating all infestations resulting in an efficacy of $100 \%$ on Day 84. No statistically significant ( $p>0.05$ ) differences in live mite counts were observed between the two IVP treated groups. Concurrent with this study, the aforementioned multicenter, clinical efficacy field study utilizing regular monthly-dosing was conducted and provided similar results. It was conducted at 6 sites in France (3), Italy (1) and Poland (2). In this study, 31 dogs were treated with NexGard and 19 dogs were treated with NexGard Spectra. At the Day 84 field assessment ( +4 days) after receiving 3 monthly doses $(0,28,56)$ of either NexGard or NexGard Spectra, the 50 dogs experienced a $>97.5 \%$ reduction in live mite counts [13].

In conclusion, three monthly treatments with NexGard or NexGard Spectra against generalized demodicosis in dogs were highly effective resulting in a 99.9\% and 100\% efficacy against mites, respectively. Both treatments resulted in a marked reduction of skin lesions and $>90 \%$ hair-regrowth at three months after the initial treatment.

\section{Conflicts of Interest}

The authors declare no conflicts of interest regarding the publication of this paper.

\section{References}

[1] Leydig F. (1859) Über Haarsackmilben und Krätzmilben. Archiv für Naturgeschichte, 25,338 .

[2] Mueller, R., Meyer, D., Bensignor, E. and Sauter-Louis, C. (2009) Treatment of Canine Generalised Demodecosis with a "Spot-On" Formulation Containing 10\% Moxidectin and 2.5\% Imidacloprid (Advocate, Bayer Healthcare). Veterinary Dermatology, 20, 441-446. https://doi.org/10.1111/j.1365-3164.2009.00790.x

[3] Mueller, R.S., Bensignor, E., Ferrer, L., Holm, B., Lemarie, S., Paradis, M. and Shipstone, M.A. (2012) Treatment of Demodicosis in Dogs: 2011 Clinical Practice Guidelines. Veterinary Dermatology, 23, 86-96. https://doi.org/10.1111/j.1365-3164.2011.01026.x

[4] Paradis, M. (1999) New Approaches to the Treatment of Canine Demodicosis. Veterinary Clinics of North America: Small Animal Practice, 29, 1425-1436. https://doi.org/10.1016/S0195-5616(99)50136-8

[5] Guaguère, E. and Beugnet, F. (2008) Parasitic Skin Conditions. In: Guaguère, E., Prélaud, P. and Craig, M., Eds., A Practical Guide to Canine Dermatology, Kalianxis, Paris, 179-226.

[6] Letendre, L., Harriman, J., Huang, R., Drag, M. and Larsen, D.L. (2014) The Intravenous and Oral Pharmacokinetics of Afoxolaner, a Novel Isoxazoline, Used as a Monthly Chewable Antiparasitic for Dogs. Veterinary Parasitology, 201, 190-197. https://doi.org/10.1016/j.vetpar.2014.02.021

[7] Drag, M., Saik, J., Harriman, J. and Larsen, D. (2014) Safety Evaluation of Orally Administered Afoxolaner in 8-Week-Old Dogs. Veterinary Parasitology, 201, 198-203. https://doi.org/10.1016/j.vetpar.2014.02.022 
[8] European Medicines Agency (2014) Nexgard ${ }^{\circledR}$ Summary of Product Characteristics. http://www.ema.europa.eu/docs/en_GB/document_library/EPAR_-_Product_Infor mation/veterinary/002729/WC500164067.pdf

[9] Beugnet, F., Halos, L., Larsen, D. and de Vos, C. (2016) Efficacy of Oral Afoxolaner for the Treatment of Canine Generalised Demodicosis. Parasite, 23, 14. https://doi.org/10.1051/parasite/2016014

[10] BiostaTGV, University Paris VI. (2018) https://biostatgv.sentiweb.fr/?module=tests

[11] EMEA. VICH Topic GL9 (GCP) (2000) Guideline on Good Clinical Practices. The European Agency for the Evaluation of Medicinal Products (EMWA/CVMP/VICH/ 595/98-Final).

http://www.ema.europa.eu/docs/en_GB/document_library/Scientific_guideline/200 9/10/WC500004343.pdf

[12] Chavez, F. (2016) Case Report of Afoxolaner Treatment for Canine Demodicosis in Four Dogs Naturally Infected with Demodex canis. Journal of Applied Research in Veterinary Medicine, 14, 123-127.

[13] Lebon, W., Beccati, M., Bordeau, P., Brement, T., Bruet, V., Cekiera, A., Crosaz, O., Darmon, C., Guillot, J., Mosca, M., Pin, D., Popiel, J., Handwerker, D.P., Larsen, D., Tielemans, E., Beugnet, F. and Halos, L. (2018) Efficacy of Two Formulations of Afoxolaner (NexGard ${ }^{\circledR}$ and NexGard Spectra ${ }^{\circledR}$ ) for the Treatment of Generalised Demodicosis in Dogs, in Veterinary Dermatology Referral Centers in Europe. Parasites \& Vectors, 11, 506. https://doi.org/10.1186/s13071-018-3083-2 